\title{
Research on Simulation and Experiment of Hydro-pneumatic Spring Thermodynamic Characteristics
}

\author{
Xiangrui Cheng ${ }^{a}$, Qinhe Gao ${ }^{b}$ and Wenxin Qian ${ }^{c}$ \\ Lab. of Armament Launch Theory \& Technology, National Key Discipline, Rocket Force University of \\ Engineering, Shanxi Xi'an 710025, China \\ a3100622856@qq.com, b851457240@qq.com, “53873696@qq.com
}

\begin{abstract}
In view of analyse the theory of calorigenic and heat dissipating, take temperature effects of oil viscosity and density into the thermodynamic model considering a phenomenon that the hydro-pneumatic spring damaged in the bench test by temperature rise too high. Designing a bench test of hydro-pneumatic spring thermodynamic characteristic to test and verify the model. The results show that the calorigenic theory, main heating is holes throttling damping effect; the correctness of hydro-pneumatic spring thermodynamic model is verified by compared the results of simulation and bench test. It provides basis theoretical for further research of hydro-pneumatic spring thermodynamic characteristics.
\end{abstract}

Keywords: Hydro-pneumatic spring; Calorigenic theory; Thermodynamic model; Temperature rise characteristic; Thermal equilibrium; Bench test.

\section{Introduction}

The temperature of the special vehicle mainly elastic element, hydro-pneumatic spring will rise significantly under complicated working condition after a period of time. This article is based on the fact and combined with relevant theory of thermodynamics, analyses and verify the theory of calorigenic and heat dissipating and temperature rise characteristic by modeling and simulation and experimental of hydro-pneumatic spring, which can avoid the temperature of hydro-pneumatic rise too high to damage.

In the study of thermodynamics characteristics of hydro-pneumatic spring, Chen Yi-jie, etc. [1] of BIT, who based on the laws of thermodynamics to analysis the damping adjustable hydro-pneumatic spring's structural parameters such as frequency, environment, and cylinder on the influence of thermodynamics characteristics. Yao Ming-tao, etc. [2,3] of BIT, researched the thermal physical property of automotive shock absorber based on heat transfer theory; Huang Xu-xia, etc. [4] of Bei-jing university of science and technology, which modeling the hydro-pneumatic spring more accurately deacribes the thermal characteristics by region and parametric method. The hydro-pneumatic structure in this paper as shown in figure 1, through tubing connection between cylinder and accumulator. 


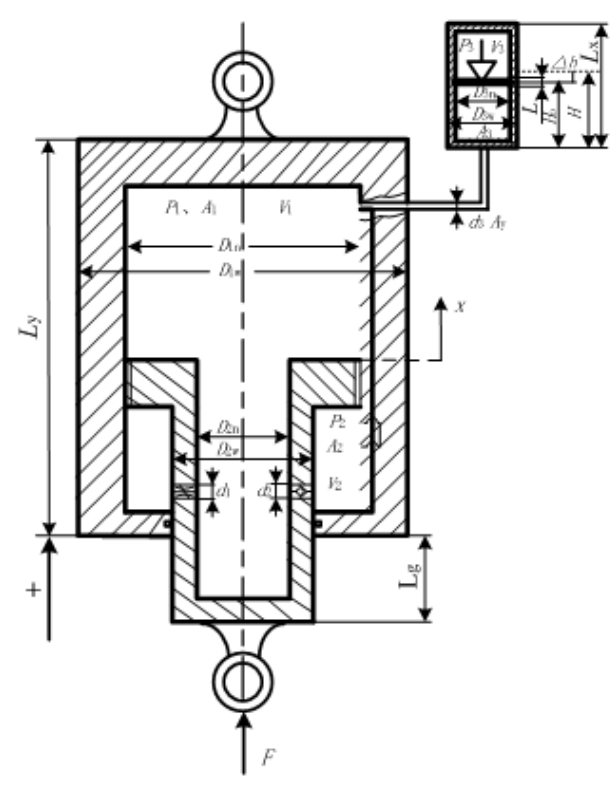

Figure 1 single chamber hydro- pneumatic spring structure

\section{Analysis thermal equilibrium mechanism of hydro-pneumatic spring}

Under the effect of external excitation load, hydro-pneumatic spring mainly divided into compression and tensile stroke. Primarily through the oil flows through damping orifice throttling effect of holes, friction heat and gas compression; Heat dissipation can be divided into gas and liquid of different dissipation ways. The mechanism of calorigenic and heat dissipation as shown in figure 2 and figure 3.

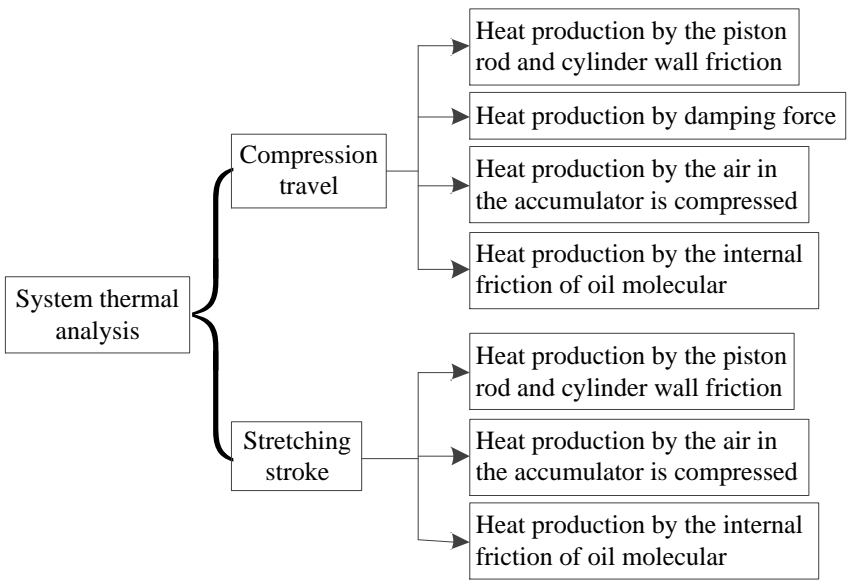

Figure 2 Hydro-pneumatic spring calorigenic mechanism

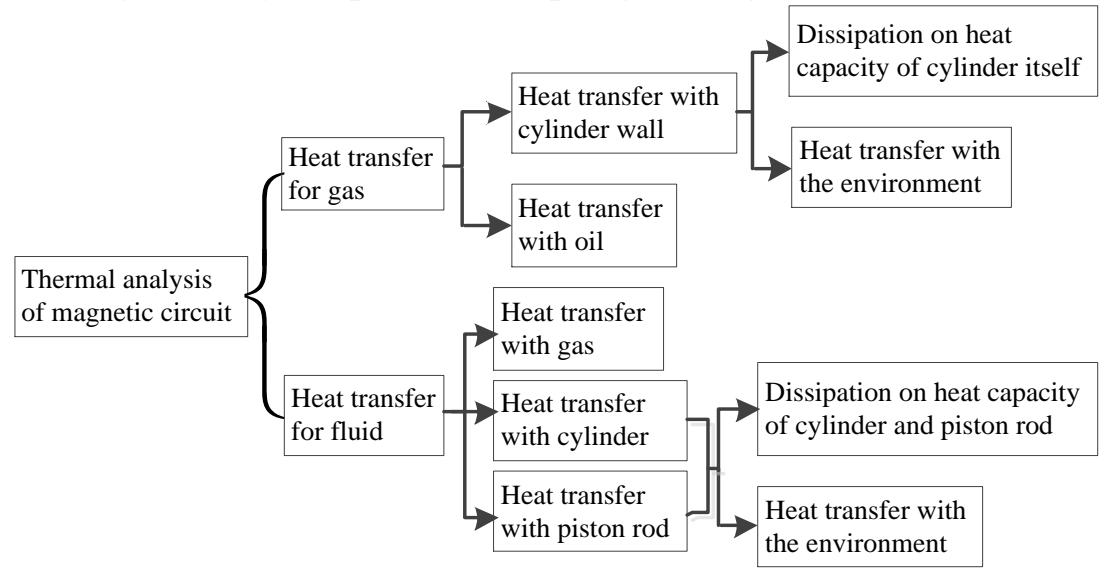

Figure 3 Hydro-pneumatic spring heat dissipation ways 
The whole calorigenic and heat dissipation is simultaneous, so the hydro-pneumatic spring will rose to a certain temperature and into balance eventually, reach thermal equilibrium state.

\section{Modeling of hydro-pneumatic spring thermodynamic characteristic}

According to figure 1, modeling the thermodynamic characteristic of hydro-pneumatic spring with its structure. Assumes the oil in main oil chamber, annular oil cavity and accumulator are respectively for isothermal integral.

\subsection{Modeling the characteristic of oil viscosity and density with temperature}

The oil viscosity/density-temperature characteristics can be expressed by the empirical formula [1] as follows:

$$
\begin{aligned}
& \mu_{T}=\mu_{o} e^{-o\left(T_{y}-T_{o}\right)} \\
& \rho=\rho_{o}\left[1-\beta\left(T_{y}-T_{o}\right)\right]
\end{aligned}
$$

\subsection{Thermodynamic model for system}

For a system, according to thermodynamics law of conservation of energy, system calorific minus the energy loss per unit time is equal to the increase of internal energy.

$$
\frac{d W_{z}}{d t}-\frac{d Q}{d t}=\frac{d U_{z}}{d t}
$$

\subsubsection{Take accumulator gas as the research object to analysis the thermodynamic}

According to the research of literature [1], use correction coefficient of van DE real gas state equation to express the gas pressure in the accumulator.

$$
P_{3}=\frac{R_{g} T}{v-b}-\frac{a}{v^{2}}
$$

Which $a \& b$ are van DE constant, depending on the type of gas. $R_{g}$ for the gas onstant, for nitrogen, $\mathrm{a}=456.37 \mathrm{~m}^{6} \mathrm{~Pa} / \mathrm{kg}^{2}, b=0.00361 \mathrm{~m}^{3} / \mathrm{kg}, \mathrm{R}_{\mathrm{g}}=296.77 \mathrm{~J} / \mathrm{kg} \cdot \mathrm{K}$.

According to the gas general equation of thermodynamics, unit time the internal energy increment of gas and the outside world for gas work can be represented as:

$$
\left\{\begin{array}{l}
\frac{d U_{3}}{d t}=\left(m_{q} c_{q v}+m_{x} c_{x}\right) \frac{d T_{3}}{d t}+\frac{m_{q}{ }^{2} a}{V_{3}^{2}} \frac{d V_{3}}{d t} \\
\frac{d W_{3}}{d t}=p_{3} A_{3 n} \dot{H}=p_{3} A_{2 w} \dot{x}
\end{array}\right.
$$

\subsubsection{Take oil as the research object to analysis the thermodynamic}

Oil flows through the damping holes, check valve and tubing, and according to the damping effect equation, through the damping hole and check valve of the oil flow rate is respectively:

$$
\begin{aligned}
& Q_{z}=C_{z} A_{z} \sqrt{\frac{2\left(p_{2}-p_{1}\right) \operatorname{sign}(\dot{x})}{\rho}} \\
& Q_{d}=\frac{1}{2} C_{d} A_{d} \sqrt{\frac{2\left(p_{2}-p_{1}\right) \operatorname{sign}(\dot{x})}{\rho}}(1-\operatorname{sign}(\dot{x}))
\end{aligned}
$$

Damping hole type $\mathrm{Cz}, \mathrm{Cd}$, respectively, take 0.61 .

Consider the incompressibility of the oil, the oil flowing out of hydro-pneumatic spring cylinder is equal to the oil flowing in accumulator, traffic inflows/outflows of accumulator and as follows:

$Q_{y}=\left(A_{1 n}-A_{4}\right) \dot{x} \operatorname{sign}(\dot{x})$

Accumulator line between cylinder and frictional pressure loss and local pressure loss [5], represented as:

$$
\begin{aligned}
& p_{j}=\frac{1}{2} \rho\left(\frac{Q_{y}}{A_{y}}\right)^{2}\left\{\xi_{1}[1-\operatorname{sign}(\dot{x})]-\xi_{2}[1+\operatorname{sign}(\dot{x})]\right\} \\
& p_{y}=\frac{\rho v_{c 1}{ }^{2} \lambda_{c 1} l_{3} \operatorname{sign}(\dot{x})}{2 d_{3}}
\end{aligned}
$$

In the equation, Ay repress cross-sectional area of the tubing, $\mathrm{m} 2 ; \xi 1$ and $\xi 2$ repress pressure lose coefficient, $\xi_{1}=1.0$ and $\xi_{2}=0.5 ; 1_{3}$-tubing length; $\lambda_{\mathrm{cl}}$-tubing frictional resistance coefficient. 
Through equation (6) (10), can derived calorific of damping effect and oil internal energy increment per unit time as shown [6]:

$$
\left\{\begin{array}{l}
\frac{d W_{y}}{d t}=\sum_{i=1}^{n} \Delta p_{i} \cdot Q_{i} \cdot \operatorname{sign}(\dot{x}) \\
\frac{d U}{d t}=\left(m_{y} c_{p y}+m_{g} c_{g}\right) \frac{d T_{y}}{d t}
\end{array}\right.
$$

Here, $m_{y}, c_{p y}$ and $m_{g}, c_{g}$ said oil respectively, specific heat capacity and the quality of the cylinder and piston rod general equivalent mass, equivalent specific heat.

\subsubsection{Friction heat}

There is friction between the piston rod and cylinder, according to the above analysis, the friction force is expressed as:

$$
F_{f}=u \pi\left[\left(p_{1}-p_{2}\right)\left(\zeta D_{1 n} b_{D}+\zeta_{1} D_{2 w} b_{m}\right)\right]
$$

Here, $\mathrm{u}$ is sealing ring friction coefficient, $\mathrm{u}=0.1 ; \mathrm{b}_{\mathrm{D}}$ is piston ring width; $\zeta$ is piston ring friction correction coefficient; $b_{m}$ is piston rod sealing ring width; $\zeta_{1}$ is piston rod sealing ring correction coefficient of friction.

The friction heat production per unit time is expressed as:

$$
\frac{d W_{f}}{d t}=F_{f} \cdot \dot{x}
$$

\subsubsection{System heat dissipation model}

According to heat dissipation ways as shown in figure 3, system basically has the following kinds of heat dissipation form:

First, heat dissipation by heat condution. Main consideration dissipation after the oil temperature in the cylinder, piston rod and the accumulator on the quantity of heat, make the system overall increase. Oil temperature for $\mathrm{T}_{\mathrm{y}}$, Material coefficient of heat transfer $\lambda$.

Cylinder of thermal conductivity, piston rod of thermal conductivity and accumulator of thermal conductivity can be expressed as:

$$
\frac{d Q_{w}}{d t}=-2 \pi L_{y} \lambda \cdot \frac{T_{n}-T_{w}}{\ln \left(D_{1 n} / D_{1 w}\right)}, \frac{d Q_{g}}{d t}=-2 \pi L_{g} \lambda \cdot \frac{T_{n}-T_{w}}{\ln \left(D_{2 n} / D_{2 w}\right)}, \frac{d Q_{x}}{d t}=-2 \pi L_{x} \lambda \cdot \frac{T_{3 n}-T_{3 w}}{\ln \left(D_{3 n} / D_{3 w}\right)}
$$

Thermal conductivity between the oil and gas through floating piston accumulator inside:

$$
\frac{d Q_{y 3}}{d t}=\lambda \cdot A_{x f} \cdot \frac{T_{y}-T_{3}}{L}
$$

Second, the surface of cylinder and the accumulator to the external environment of radiation heat. By Stephen-boltzmann laws of radiation [7], can get the cylinder and the accumulator available external radiation heat [1]:

$$
\left\{\begin{array} { l } 
{ \frac { d Q _ { g f s } } { d t } = h _ { g f s } A _ { 1 - w } ( T _ { w } - T _ { \infty } ) } \\
{ h _ { g f s } = \varepsilon _ { f } C _ { b } \frac { ( T _ { w } { } ^ { 2 } + T _ { \infty } { } ^ { 2 } ) ( T _ { w } + T _ { \infty } ) } { 1 0 0 ^ { 4 } } }
\end{array} \quad \left\{\begin{array}{l}
\frac{d Q_{x f s}}{d t}=h_{x f s} A_{x_{-} w}\left(T_{3 w}-T_{\infty}\right) \\
h_{x f s}=\varepsilon_{f} C_{b} \frac{\left(T_{3 w}{ }^{2}+T_{\infty}{ }^{2}\right)\left(T_{3 w}+T_{\infty}\right)}{100^{4}}
\end{array}\right.\right.
$$

Here, $\varepsilon_{\mathrm{f}}$ is thermal emissivity, $\mathrm{C}_{\mathrm{b}}$ is the blackbody radiation coefficient, $\mathrm{A}_{\mathrm{x}_{-} w}$ is accumulator contact area with the environment.

Third, convection.

(1) The convection between cylinder, accumulator outside the cylinder wall and piston rod with environment (forced convection).

According to the research of the literature [8], this kind of situation can experience formula of coefficient of heat transfer for:

$$
\left\{\begin{array} { l } 
{ h _ { w o } = \frac { \lambda _ { k } } { D _ { 1 w } } [ C \cdot R e _ { k 1 } { } ^ { n } \cdot P r _ { k } ^ { 1 / 3 } ] } \\
{ h _ { x o } = \frac { \lambda _ { k } } { D _ { 3 w } } [ C \cdot R e _ { k 3 } { } ^ { n } \cdot P r _ { k } ^ { 1 / 3 } ] }
\end{array} \quad \left\{\begin{array}{ll}
R e_{k 1}=\frac{V_{k} D_{1 w}}{v_{k}} & \text { (cylinder part air Reynolds number) } \\
\operatorname{Re}_{k 3}=\frac{V_{k} D_{3 w}}{v_{k}} & \text { (accumulator part air Reynolds number) }
\end{array}\right.\right.
$$

$\mathrm{C}$ and $\mathrm{n}$ in equation (4-23) can be gained through the look-up table 1[4]: 
Table 1 parameter $\mathrm{C}$ and $\mathrm{n}$ selection for the Reynolds number

\begin{tabular}{|c|c|c|c|c|c|}
\hline Rek & $0.4-4$ & $4-40$ & $40-4000$ & $4000-40000$ & $40000-400000$ \\
\hline $\mathrm{C}$ & 0.989 & 0.911 & 0.683 & 0.193 & 0.0266 \\
\hline $\mathrm{n}$ & 0.330 & 0.385 & 0.466 & 0.618 & 0.805 \\
\hline
\end{tabular}

To simplify the calculation, combined the radiation heat part with this part, can reduce the amount of calculation:

$$
\left\{\begin{array} { l } 
{ h _ { w o 1 } = h _ { w o } + h _ { g f s } } \\
{ h _ { w o 2 } = h _ { x o } + h _ { x f s } }
\end{array} \Rightarrow \left\{\begin{array}{l}
\frac{d Q_{w o}}{d t}=h_{w o 1} A_{1_{-} w}\left(T_{w}-T_{\infty}\right) \\
\frac{d Q_{x o}}{d t}=h_{w o 2} A_{3-w}\left(T_{3 w}-T_{\infty}\right)
\end{array}\right.\right.
$$

Here, $\mathrm{A}_{1_{-} \mathrm{w}^{-}}$heat transfer surface area of cylinder and the environment, $A_{I_{-} w}=\pi D_{l w} L_{y} ; \mathrm{A}_{3 \_} \mathrm{w}^{-}$heat transfer surface area of accumulator and the environment, $\mathrm{A}_{3 \_\mathrm{w}}=\pi \mathrm{D}_{3 \mathrm{w}} \mathrm{L}_{\mathrm{x}}$.

Similarly, the piston rod and the environment between the convective heat release is:

$$
\frac{d Q_{g o}}{d t}=h_{g k o} A_{2_{-} w}\left(T_{w}-T_{\infty}\right)
$$

(2) Convection between the lining and the oil cylinder, piston rod, accumulator.

Walls, accumulator with the oil cylinder belongs to tube forced convection heat transfer, available state of laminar flow and turbulent flow conditions forced convection coefficient respectively as follows(Here, $\lambda_{\mathrm{y}}$ for oil thermal conductivity; $\mathrm{v}_{\mathrm{y}}$ is oil viscosity; $\mathrm{P}_{\mathrm{ry}}$ for oil Planck's constant):

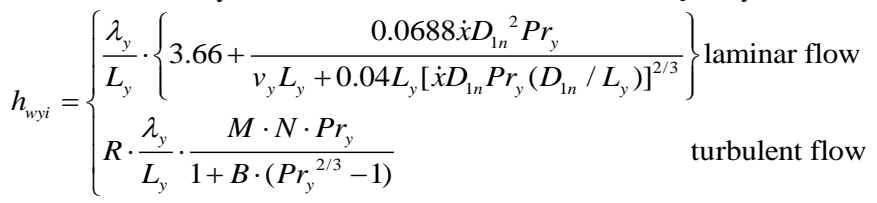

$$
\begin{aligned}
& R=1+\left(\frac{D_{11}}{L_{y}}\right)^{0.7}, N=\frac{\dot{x} D_{1 n}}{v_{y}}-1000,{ }_{M}=\frac{1}{8}\left(0.79 \ln \left(\frac{\dot{x} D_{1 n}}{v_{y}}\right)-1.64\right)^{-2}, B=25.4 \sqrt{2}\left[0.79 \ln \left(\frac{\dot{x} D_{1 n}}{v_{y}}\right)-1.64\right]^{-1} \text {. }
\end{aligned}
$$

Thus available: $\frac{d Q_{w i}}{d t}=h_{w y i} A_{1_{-} n}\left(T_{y}-T_{n}\right), \frac{d Q_{g i}}{d t}=h_{w y i} A_{2_{-} n}\left(T_{y}-T_{n}\right), \frac{d Q_{x i}}{d t}=h_{g q i} A_{3_{-} n}\left(T_{3}-T_{3 n}\right)$.

Simultaneous above formula and arrange them, thermodynamic model for the available systems:

$$
\begin{aligned}
& \int d T_{3}=\frac{1}{\left(m_{q} c_{q v}+m_{x} c_{x}\right)}\left[B_{y 3} T_{y}-\left(B_{x}+B_{y 3}\right) T_{3}+p_{3} A_{2 w} \dot{x}+B_{x} T_{\infty}-\frac{a m_{q}{ }^{2}}{V_{3}^{2}} \frac{d V_{3}}{d t}\right] d t \\
& d T_{y}=\frac{1}{\left(m_{y} c_{p y}+m_{g} c_{g}\right)}\left[\begin{array}{l}
B_{y 3} T_{3}-\left(B_{w}+B_{g}+B_{y 3}\right) T_{y}+F_{f} \dot{x}+ \\
\sum_{i=1}^{n} \Delta p_{i} \cdot Q_{i} \operatorname{sign}(\dot{x})+\left(B_{w}+B_{g}\right) T_{\infty}
\end{array}\right] d t
\end{aligned}
$$

In equation (17), $\quad B_{x}=\left[\frac{1}{A_{3-w} h_{w o 2}}+\frac{\ln \left(D_{3 w} / D_{3 n}\right)}{2 \pi L_{x} \lambda}+\frac{1}{A_{3-n} h_{g i i}}\right]^{-1}, \quad B_{w}=\left[\frac{1}{A_{1-w} h_{w o 1}}+\frac{\ln \left(D_{1 w} / D_{1 n}\right)}{2 \pi L_{y} \lambda}+\frac{1}{A_{1-n} h_{w i j}}\right]^{-1}, \quad B_{y 3}=\frac{\lambda \cdot A_{x f}}{L}$, $B_{g}=\left[\frac{1}{A_{2 \_w} h_{g k o}}+\frac{\ln \left(D_{2 w} / D_{2 n}\right)}{2 \pi L_{g} \lambda}+\frac{1}{A_{2 \_n} h_{w v i}}\right]^{-1}$.

\section{Thermodynamic properties and experimental research of hydro-pneumatic spring}

According to the above modeling and parameter setting, using iteration algorithm, the process as shown in figure 4.

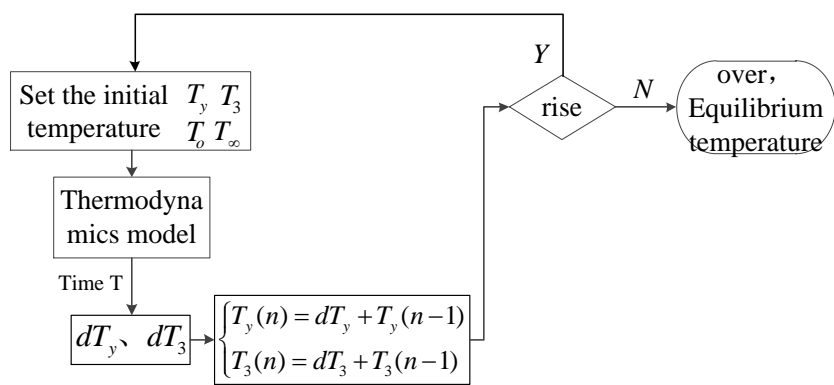

Figure 4 process of iterative algorithm simulation spring system simulation 


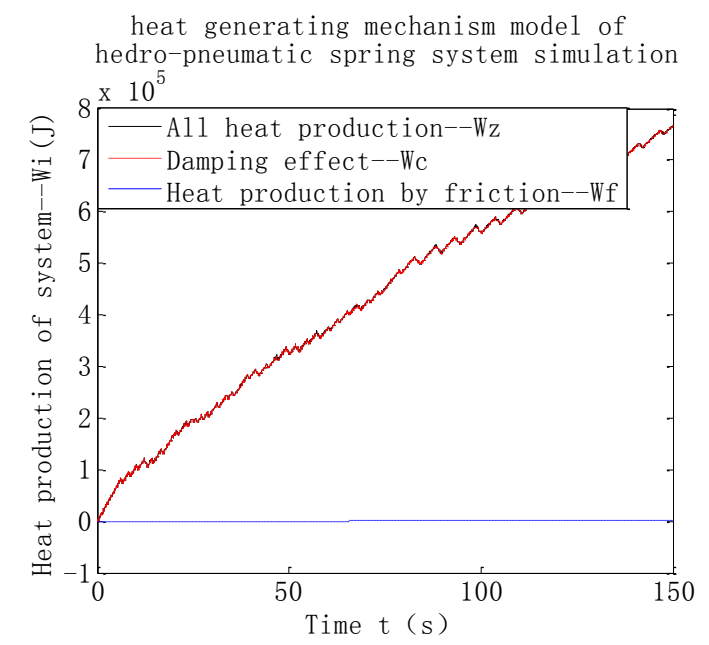

Figure 5 heat generating mechanism model of hedro-pneumatic

Setting time 150s in the simulation of thermal mechanism, setting amplitude $0.05 \mathrm{~m}$ and frequency $2 \mathrm{~Hz}$; The thermal equilibrium characteristics simulation time is set to $3000 \mathrm{~s}$, amplitude of $0.01 \mathrm{~m}$ and $0.03 \mathrm{~m}$, frequency of $2 \mathrm{~Hz}$, get the heat generating mechanism and heat balance model simulation curve as shown in figure 5,6 , respectively.

According to the figure 5 shows that the system total calorific belongs to the algebraic sum of the process, the total heat as the working time and increasing, energy conversion, because there is relative motion will be born in this performance for hedro-pneumatic spring, and the damping effect makes the system get hot (red dotted line) than the friction between the piston and cylinder wall high calorific (blue lines), and faster; Although the friction heat in the process of the whole movement uninterrupted, also keep growth trend, but in comparison, the system total calorific percentage is very small, shows that the piston in process design and processing of special processing, reduce the energy loss in the system due to this part of the reason, to show that the system work, the main reason of heat production is damping effect of the throttle in the system.

Above all, as shown in figure 6 for hydro-pneumatic spring heat balance model simulation curve, the corresponding oil density change process with time shown in figure 7.

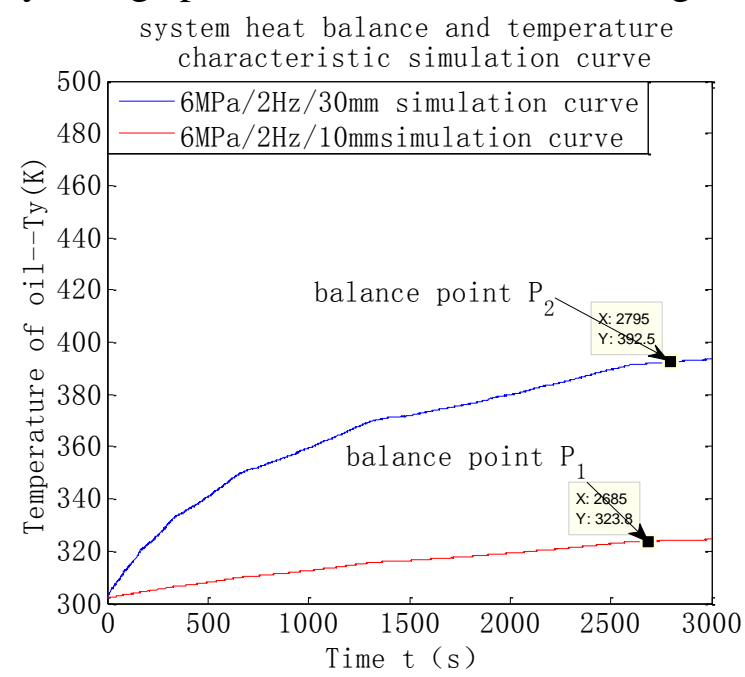

Figure 6 system heat balance and temperature characteristic simulation curve 


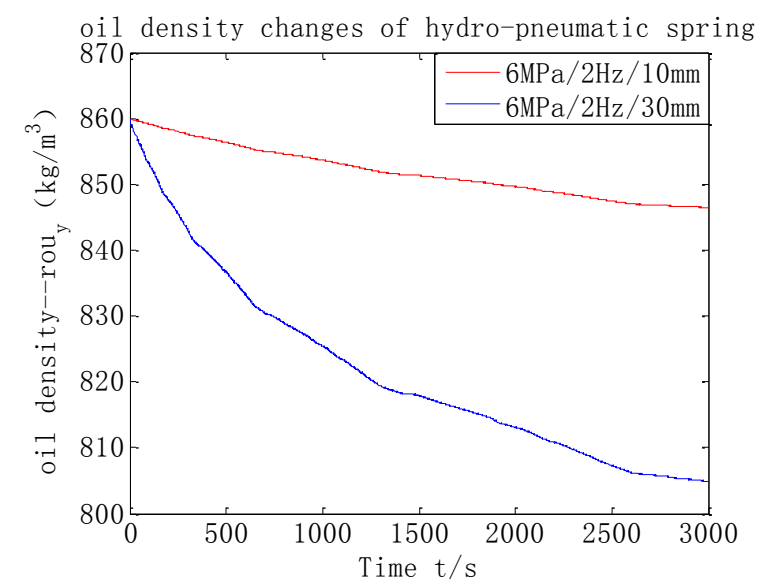

Figure 7 oil density changes of hydro-pneumatic spring

In figure 6, the system under the external excitation, the temperature will gradually rise (before point $\mathrm{P}$ ), but as the point $\mathrm{P}$ after temperature reached in a state of dynamic balance. Under the condition $(6 \mathrm{MPa} / 2 \mathrm{~Hz} / 10 \mathrm{~mm})$ of the simulation, system reached the condition of balance of time is about $2685 \mathrm{~s}$, the balance temperature $323.8 \mathrm{~K}\left(50.65^{\circ} \mathrm{C}\right)$; and in $6 \mathrm{MPa} / 2 \mathrm{~Hz} / 30 \mathrm{~mm}$, system reached the condition of balance of time is about $2795 \mathrm{~s}$, the balance temperature $392.5 \mathrm{~K}\left(119.35^{\circ} \mathrm{C}\right)$, it is easy to make the hydro-pneumatic spring damaged under the temperature. Sealing element is easy loss efficacy under high temperature and affect its lifetime. Therefore, research on characteristics of hydro-pneumatic spring heat balance is very necessary and meaningful.

Figure 7 illustrates the system oil density change with the temperature change, and finally balanced with temperature balance.

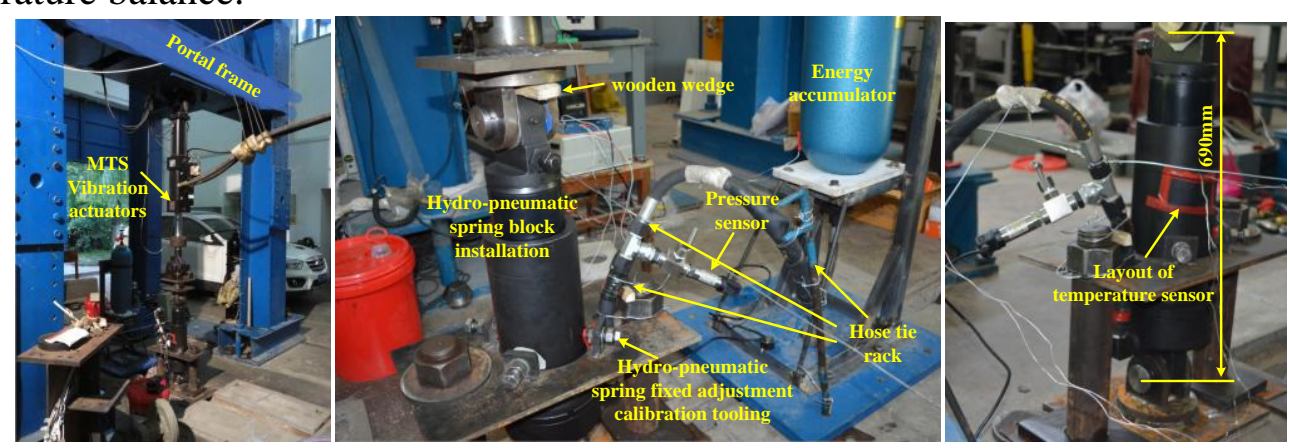

Figure 8 thermodynamic characteristics of bench test equipment and its installation, physical sensor placement

Based on the above theory, modeling and simulation research, designed thermodynamic property verification experiments for hydro-pneumatic spring, related equipment, its installation and temperature sensor arrangement installed on cylinder body physical diagram is shown in figure 8 .

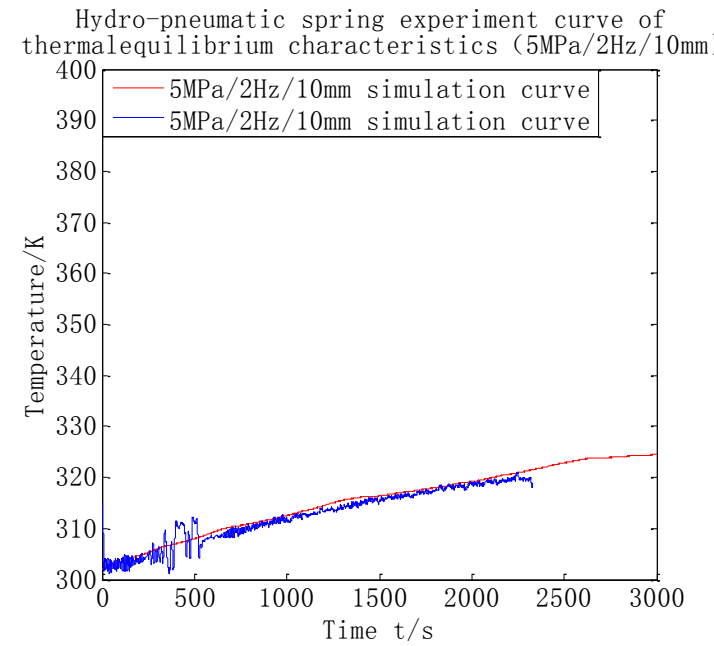

(a) $5 \mathrm{MPa} / 2 \mathrm{~Hz} / 10 \mathrm{~mm}$

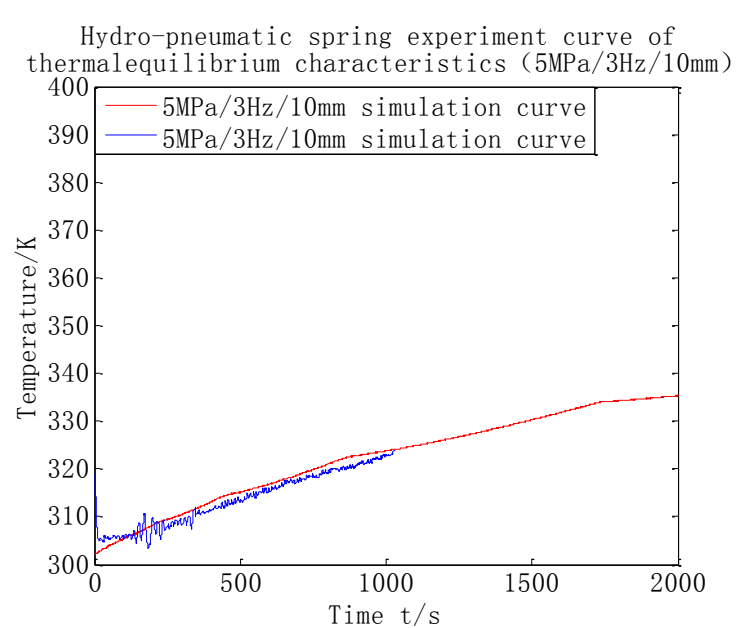

(b) $5 \mathrm{MPa} / 3 \mathrm{~Hz} / 10 \mathrm{~mm}$ 


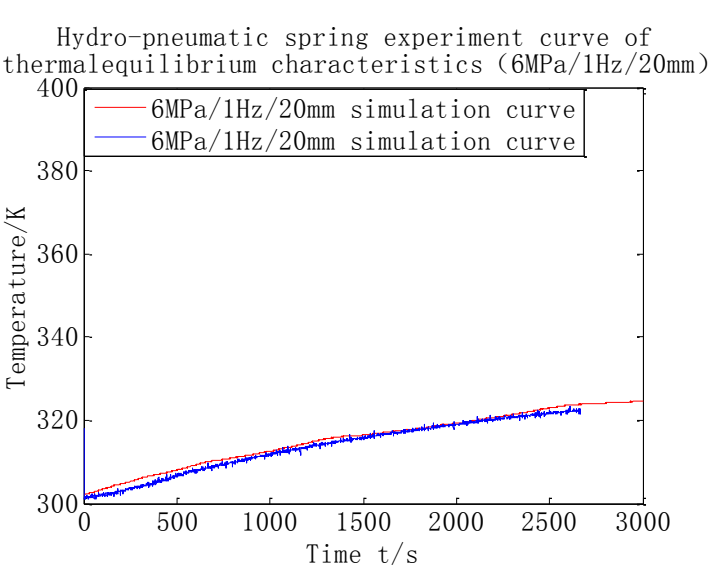

(c) $6 \mathrm{MPa} / 1 \mathrm{~Hz} / 20 \mathrm{~mm}$

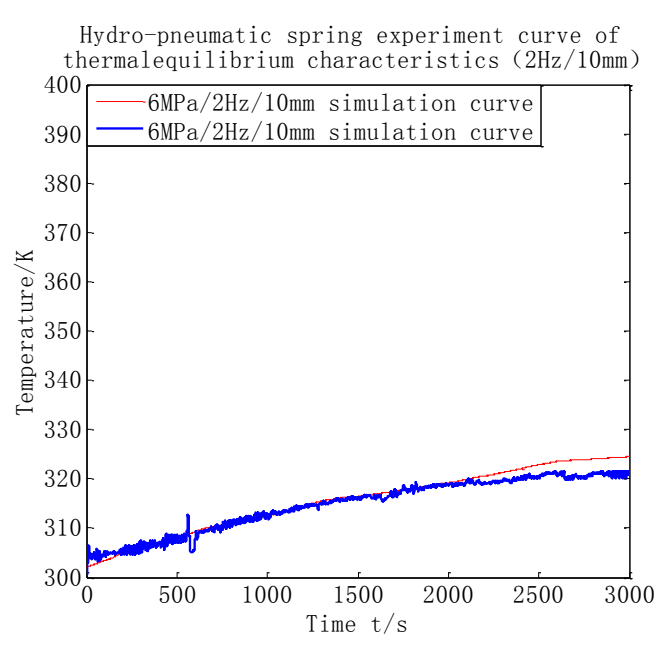

(d) $6 \mathrm{MPa} / 2 \mathrm{~Hz} / 10 \mathrm{~mm}$

Figure 9 simulation compared with the experimental curves

According to the experimental conditions, 5MPa/2 Hz/10mm, 5MPa/3Hz/10mm, $6 \mathrm{MPa} / 1 \mathrm{~Hz} / 20 \mathrm{~mm}$ and $6 \mathrm{MPa} / 2 \mathrm{~Hz} / 10 \mathrm{~mm}$ four groups of temperature rise experiment was carried out. Considering the hydro- penumatic spring may easily damaged when temperature rise too high for frequency and amplitude is too large, the first four groups are completed to temperature increase to $50{ }^{\circ} \mathrm{C}$ to stop the experiment. The experiments and simulation curves as shown in figure 9 (a d) respectively.

As shown in figure 9 (d), for its complete loading temperature thermal equilibrium experiment curve (blue line), when they reach thermal equilibrium temperature of $320.3 \mathrm{~K}$, and compared with the calculation result of simulation experiment contrast (red line), in the same conditions of hydro-pneumatic spring (oil) thermal equilibrium temperature of $324.2 \mathrm{~K}$, just $3.9 \mathrm{~K}$ difference; Under the condition of other conditions as shown in figure $9(\mathrm{a} \sim \mathrm{c})$ experimental curve and simulation curve contrast, better alignment, in order to illustrate in the range of allowable error verifies the correctness and reliability of the theoretical model.

\section{Conclusion}

This paper research on simulation and experiment of hydro-pneumatic spring thermodynamic characteristics and the mechanism of heat generating, which based on the phenomenon of hydro-pneumatic spring temperature rise. The conclusion verify the accuracy of theoretical modeling, are able to provide a reliable theoretical basis to avoid hydro-pneumatic spring thermal damage, prolong service life and the further study of the thermodynamic properties.

\section{References}

[1]. Chen Yi-jie, Gu Liang, Guan Ji-fu. Research on Natural Convection Thermodynamic Model of Hydro-pneumatic Spring [J]. Journal of System Simulation, 2008(08): 4198-4206.

[2]. Yao Ming-tao, Gu Liang, Wang Guo-li. Research on Influence Rules of Design Parameters of Vehicular Shock Absorber on Its Temperature Rising[J]. Machinery Design \& Research, Vol.26, No.5, 2010:109-113.

[3]. Yao Ming-tao, Gu Liang, Guan Ji-fu. Research on Thermal-Mechanical Coupled Characteristics of Military Vehicle Suspension System [J]. Transactions of Beijing Institute of Technology, Vol.32, No.3, Mar. 2012.

[4]. Huang Xiaxu, Shen Yanhua, Yang Jue, etal. Thermal analysis of hydro-pneumatic suspension system for dumper based on a lumped-parameter thermal model [J]. Transactions of the Chinese Society of Agricultural Engineering (Transactions of the CSAE), Vol.29, No.10, 2013: 64-70. 
[5]. Zhang Li-ping. Concise manual hydraulic engineering [M].Beijing:chemical industry press, 2011.

[6]. Gao Jun-yi, Lian Jin-Yi, Wang Si-min. All terrain crane hydraulic system heat balance calculation of hydro-pneumatic suspension [J]. Journal of lifting the transport machinery, 2015 (8): 30-35.

[7]. Liu Xiao-hong, Xu Tao. Fluid mechanics and heat engineering [M].Beijing: China Machine Press, 2012, 126-172.

[8]. Holman J P. Heat Transfer [M].9th ed. Beijing: China Machine Press, 2005, 139-156. 